\title{
REVIEW OF ICE CHALLENGES AND ICE MANAGEMENT IN PORT AREAS
}

\author{
Cayetana Ruiz de Almirón de Andrés ${ }^{1}$, Sami Saarinen², Arto Uuskallio ${ }^{3}$
}

\begin{abstract}
Winter navigation in harbors located in arctic areas becomes very challenging due to cold weather, ice drift, brash ice growth, ice collar formation in wharves and icing of structures and equipment. The loading frequency and nature of the cargo vessel traffic is affecting in the ice management needs in the harbour. There are no standard solutions for ice management in harbor areas and each location must be locally studied simultaneously with the port design identifying the associated ice challenges. This work brings together the challenges related to winter navigation in icecovered waters and ice management methods currently used in Arctic harbors.
\end{abstract}

Keywords: port areas; ice management; brash ice; ice barriers; winterization, icebreaker.

\section{INTRODUCTION}

In harbors located in arctic and sub-arctic areas ice forms during the winter season causing additional challenges to navigation and terminal operations in the form of ice drift, ice collars and icing. As the varying environmental conditions affect the initiation and development of these ice challenges the entire season needs to be considered, from freezing through to melting / thawing.

Sea ice is relatively close to its melting point at lower layers in the sea, but the surface is closer to air temperature (Weeks 2010). Hence the properties of the ice field vary with changes in the environmental conditions and the way the ice field has developed over the winter. Therefore, there are no standard solutions for ice management in harbor areas. Each location must be locally evaluated at an early stage of the project development and ice challenges associated with the area identified.

In addition, not only do harbor structures and onshore equipment and systems need to be specifically designed for cold areas, but also the interaction between the port and different vessels needs to be evaluated and defined according to the related ice challenges and operational requirements.

\section{ICE CHALLENGES}

The main challenges related to ice are ice drifting into harbor areas; brash ice growth in fairways and the terminal basin; ice collar formation in wharves; and icing of terminal structures and equipment. All these key aspects cause additional cost during the winter season for all parties: mooring times are longer, fuel consumption increases, ship's rudders and propellers are exposed to ice contacts (likely to be damaged), terminal structures are exposed to ice impact and icebreaker/tug assistance is needed, especially if intensive maneuvers are required for ship berthing operations. Due to higher propulsion power being used close to the port / terminal structures, the propeller wash effect is heavier in ice infested waters (increase of sea bed erosion). This must be considered in design of coastal and protective structures. Figure 1 map the key ice challenges associated to port and fairways, and the ice management methods used for each ice challenge.

\footnotetext{
${ }_{1}^{1}$ Aker Arctic Technology Inc, Helsinki, Finland. cayetana.ruizdealmiron@akerarctic.fi

2 Aker Arctic Technology Inc, Helsinki, Finland. sami.saarinen@akerarctic.fi

${ }^{3}$ Aker Arctic Technology Inc, Helsinki, Finland. arto.uuskallio@akerarctic.fi 


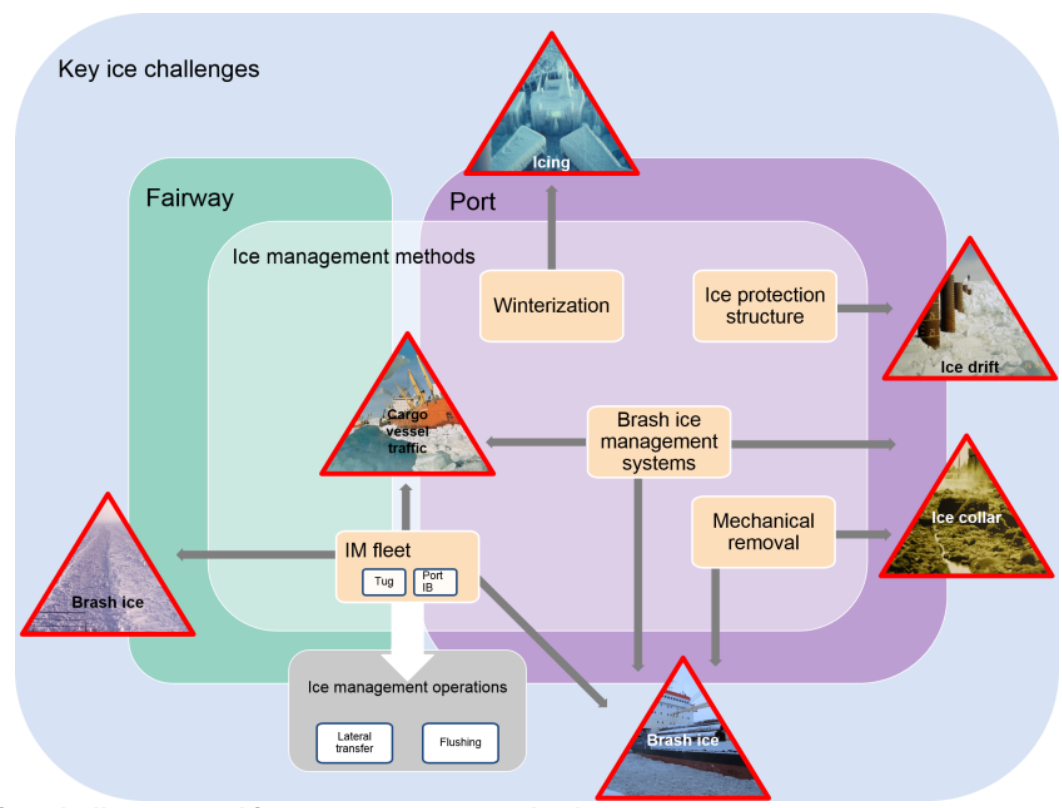

Figure 1. Key ice challenges and ice management methods.

\section{Icing}

Icing is the process of ice accumulation on the weather-exposed surfaces of vessels and its eventual result: the ice deposit frozen to the surfaces. It is a result of cooling the surfaces down to the waterfreezing temperature and the crystallization of atmospheric moisture and splash on surfaces (Mironov, 2012). Therefore, icing of terminal structures and equipment must be considering during the design process to assure operation and functionality in cold areas. Installation of winterization means as well as acquisition of suitable equipment for cold areas are required.
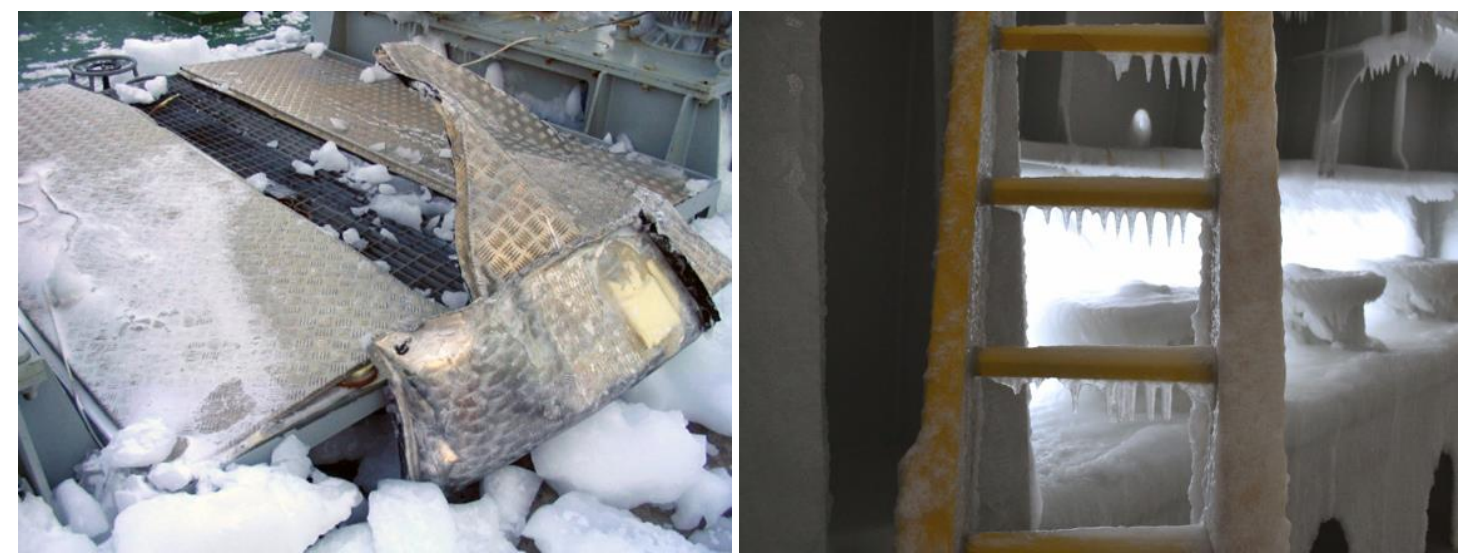

Figure 2. Left) Aluminum plates hit by falling accumulated ice on SCF Sakhalin icebreaking platform supply vessel. Right) Icing on stairs on MSV Nordica during Northwest passage voyage in October 2015.

\section{Ice drift}

In coastal areas ice drift occurs typically at the beginning of the ice season and during the melting period. In early winter the ice is still thin and easily moved by winds and currents. During the melting period, the ice is weakened because of warmer air and water temperatures, allowing fractures and displacement of floes. The most critical situation occurs if ice can drift inside the port and accumulate inside it, causing difficulties for harbor maneuvering and operations (Figure 3 left). Ice drift produces intensive loads on harbor structures as well as vessels. Vibration due to continuous ice drift needs to be evaluated during design phase (Figure 3 right). Ice barriers are a common solution designed to protected specific areas. 

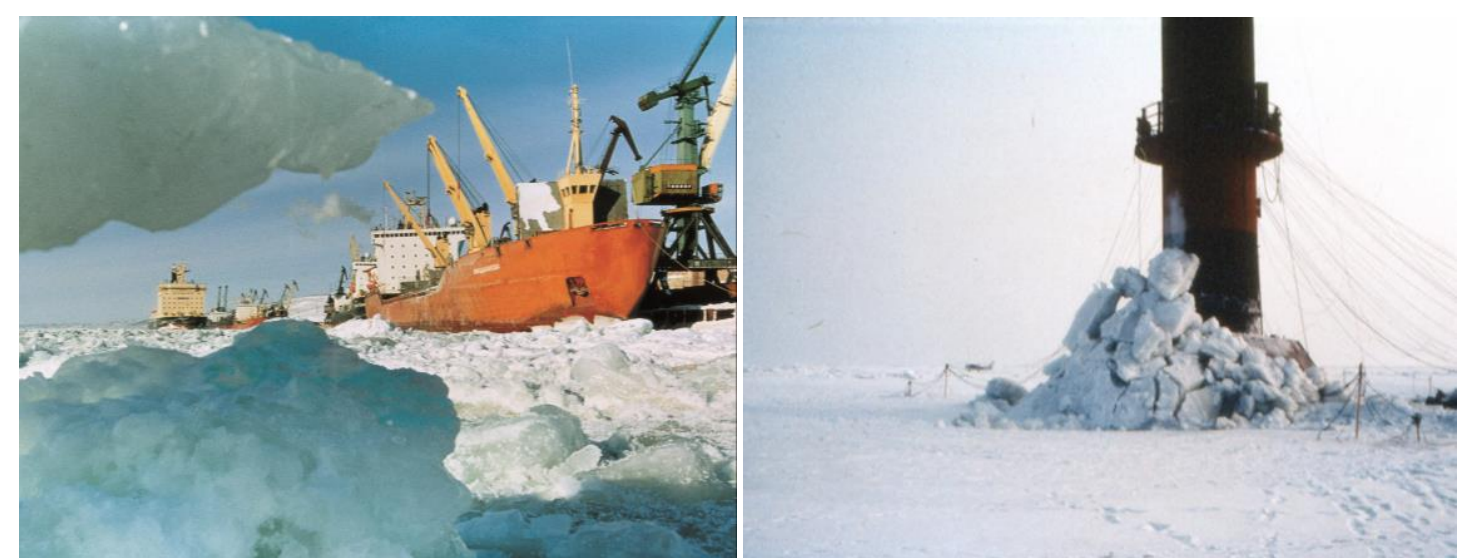

Figure 3. Left) Packed brash ice into Dudinka harbour (Russia). Right) Drifted ice accumulating against Kemi I lighthouse (Finland).

\section{Ice collars}

In harbor areas, brash ice blocks are pushed against the berth when a vessel approaches the wharf and the formation of an ice collar on the berth wall may block vessel access (Figure 4). This may become a major problem, especially in situations where positioning accuracy is essential for loading and unloading operations. Therefore, berthing is strongly affected by the ice conditions in the harbor basin, leading into increasing cost due to additional fuel consumption and greater berthing times. Reduction or removal of ice collar can be achieved by several methods as mechanical removal or implementation of brash ice management systems.

Outline of a large ship

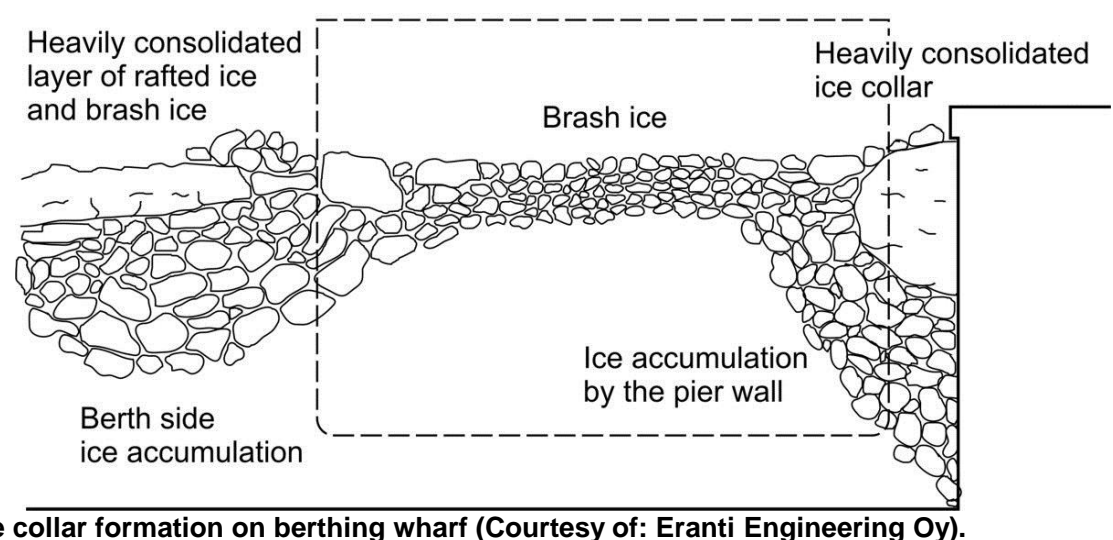

Figure 4. Ice collar formation on berthing wharf (Courtesy of: Eranti Engineering Oy).

\section{Brash ice}

Winter navigation generates brash ice in harbor basins (Figure 5 left) and approaching channels (Figure 5 right). Repeated icebreaking events and the consolidation of broken ice between ship passages result in rapid increase of brash ice thickness (Sandkvist 1981). The main factors affecting the brash ice growth (which is typically faster than natural growth of ice cover) are air temperature, breaking frequency of bas ice layer on navigation channel, ratio between width of channel and beam of the ship. As presented in Figure 1, there are different methods currently in use to manage this navigation challenge, such as mechanical removal, brash ice managements systems and availability of ice management fleet. 

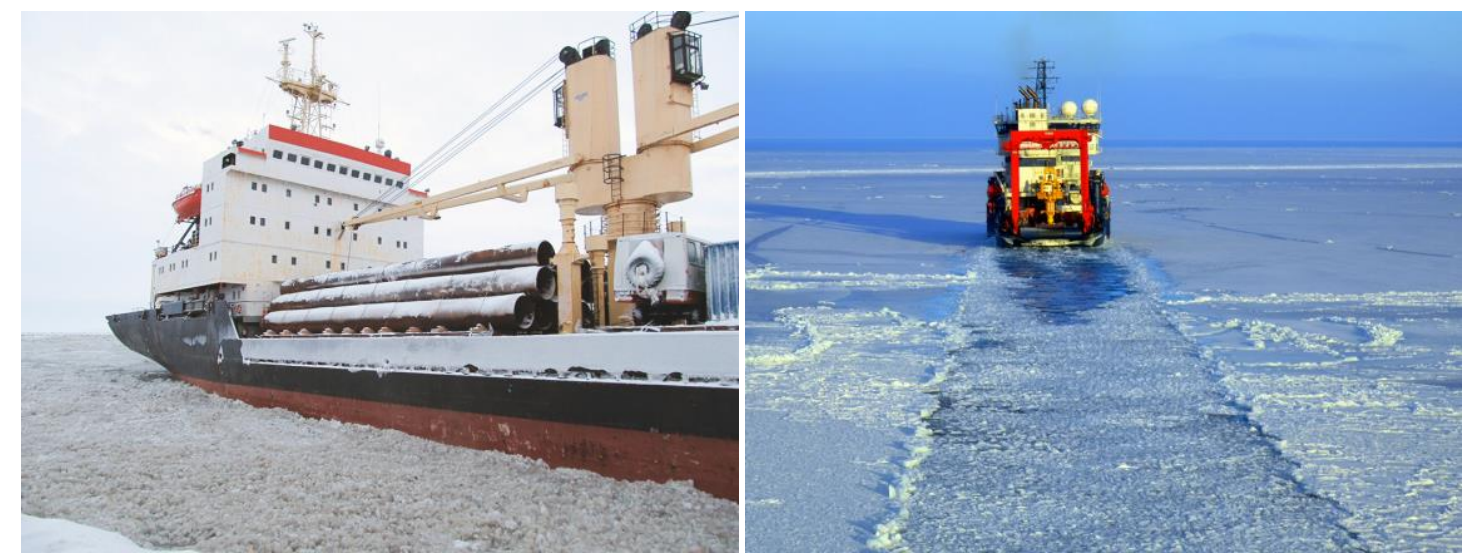

Figure 5. Left) Brash ice in Sabetta harbour, March 2015. Right) Navigation channel after MSV Fenicca. Ice blocks freeze rapidly forming brash ice.

\section{ICE MANAGEMENT}

Traffic management in ports and fairways without any kind of ice management system becomes extremely challenging when the average freezing index (CFDD) exceed $1000{ }^{\circ} \mathrm{C} \cdot$ day (Eranti 1986). Hence, to assure safety and operability, favorable location of the terminal and appropriate terminal layout needs to be considered carefully. If required, ice barriers should be designed to protect the harbor from drifting ice, based on maximum anticipated ice loads for the area. At the operational stage, ice management operations need to be carried out to clear the quayside of ice, with the consequent consumption of time. In addition, winterization of equipment and systems exposed to cold temperatures is needed to assure safe operability. There are four main methods for ice management in icy harbors: winterization, brash ice management systems, ice management fleet and mechanical removal.

\section{Winterization}

Low temperature affects to the operation of equipment, systems, personnel (safety, efficiency, accessing) and material properties. To assure safety operations under harsh winter condition on polar waters, and to minimize icing effects due to cold climate, the winterization of working areas, escape routes, passage, exposed equipment and systems, is developed from the design project level.

There are two type of winterizations methods: de-icing and anti-icing. Some systems require manual intervention to be activated or to be applied, while others use self-regulating trace heater. The main methods to remove ice (de-icing) are manual removal tools, salt, electric de-icing. On the other hand, main means to prevent/reduce icing (anti-icing) are heat tracing of pipes and equipment, space heating, salt, canvas, paints, protective structures, electric anti-icing. Figure 6 shows example of antiicing system in use.
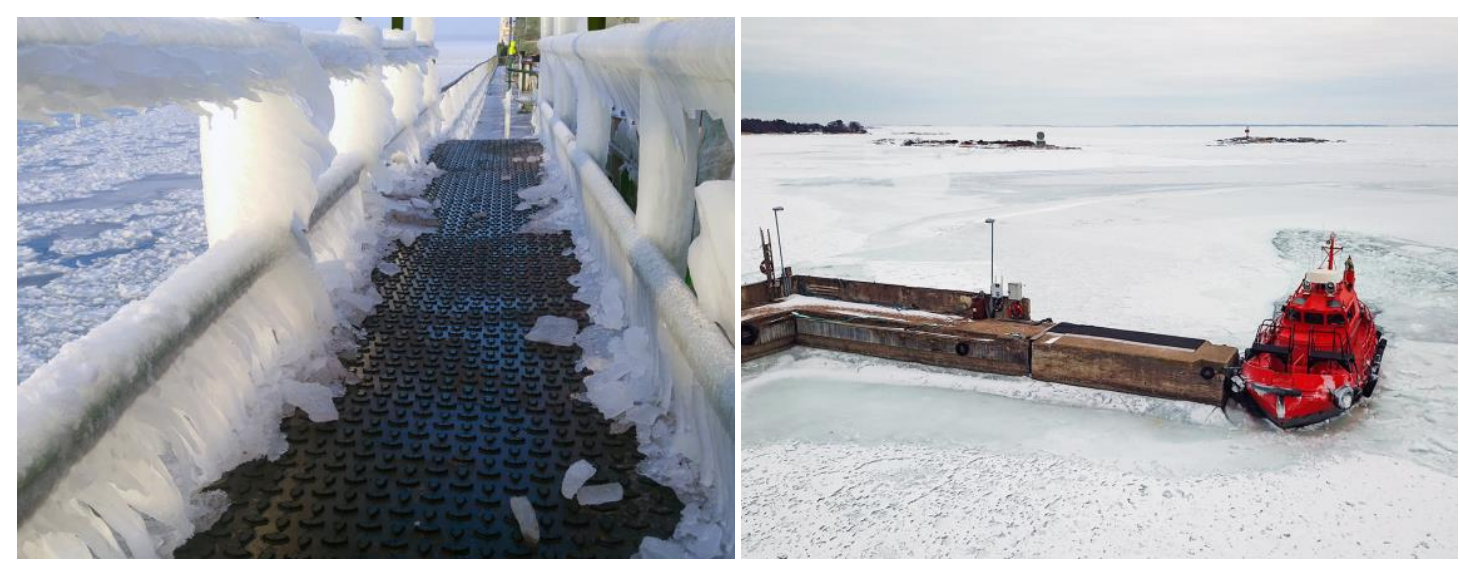

Figure 6. Left) Heated mat on deck of vessel. Right) De-icing installation for unmanned guard station in Isokari Island (Finland). (Courtesy of Starkice). 


\section{Ice protection structures}

Ice protection structures are marine structures designed to protect harbor areas from ice drift and to stand ice loads. There are different solutions to be selected based on water depth, ice field, layout of the harbour and areas to be protected, available material for construction, etc. Therefore, there can be multiple designs for vertical or inclined structures: gravity based structure, tubular sheet piles (Figure 7), cellular sheet piles, large diameter piles with skirt, filling structures, or combined concepts.

It needs to be pointed out that building too much ice barriers may lead to problems with brash ice removal, as it might accumulate in basin.

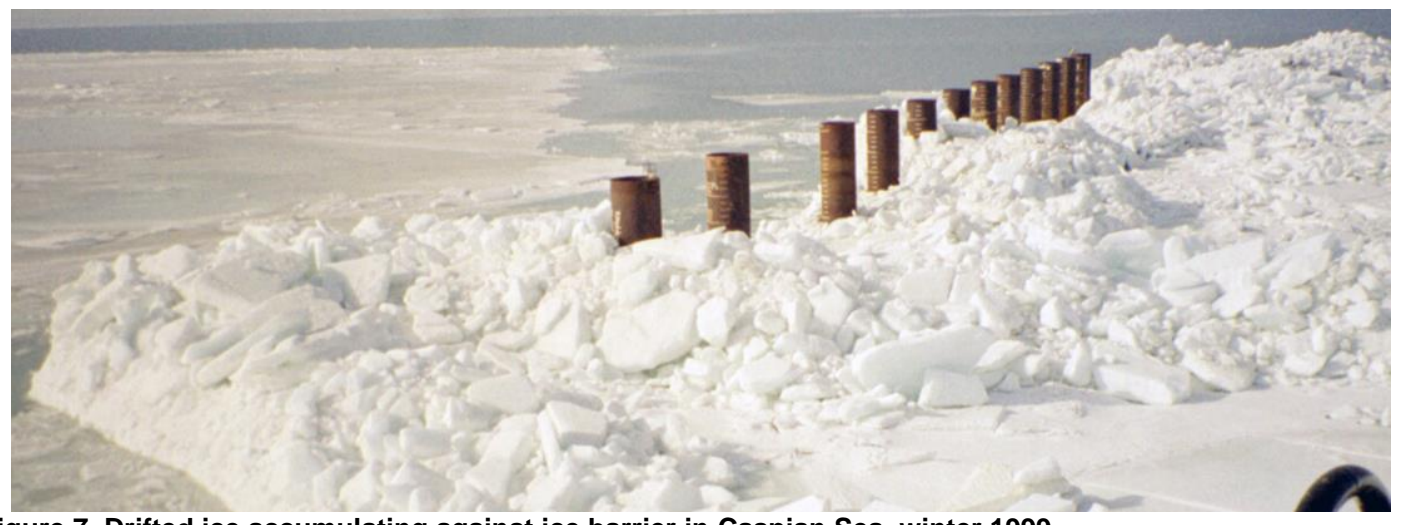

Figure 7. Drifted ice accumulating against ice barrier in Caspian Sea, winter 1999.

\section{Mechanical removal}

Mechanical removal of ice, for example using an excavator with a specifically designed scoop, can be used as a reserve system during berthing operations to remove the ice trapped between the wharf and the vessel.

The challenge of the mechanical ice removing is that it is very time consuming with low and limited work efficiency in arctic conditions. Several dump trucks and crawler cranes are required, while the amount of the brash ice is high. In addition, every load of removed brash ice is replaced by more brash ice, and the brash ice formation increases rapidly every time the ice layer is broken. Finally, when the brash ice is consolidated, the machinery might find challenging to break it in to smaller pieces suitable for the scoop size. Therefore, pre-management ice brash operations must be carried out in advance.

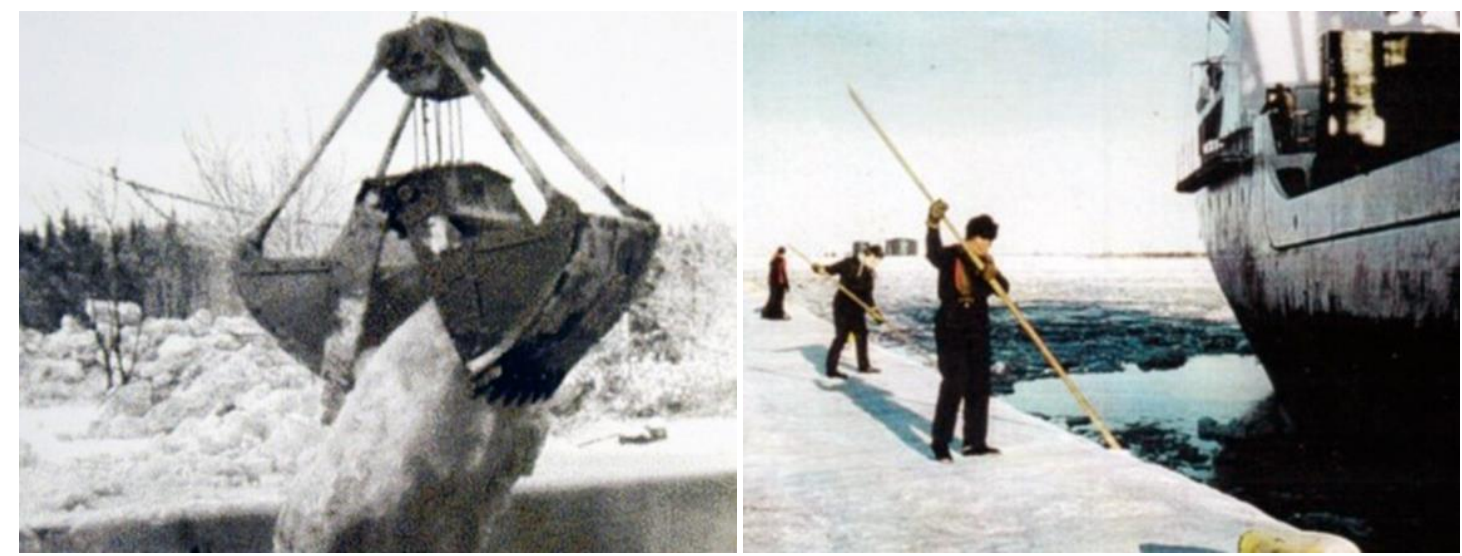

Figure 8. Left) Mechanical removal with clamshell attached in crane in Saimaa Channel, Finland. Right) Use of propellers flow and manual mechanical removal in berthing place. (Courtesy of Eranti Engineering Oy).

\section{Brash ice management systems}

Brash ice management systems are based on the generation of a surface current to circulate the thermal energy in the harbor (Pan 2009). The main benefits are reduction of brash ice cohesion and ice melting at specific locations. The main components for this arrangement are: water intake, boiler house, warm water release points, compressed air facilities and bubbler lines. This system has been successfully tested and installed in Finnish harbors (Figure 9). 


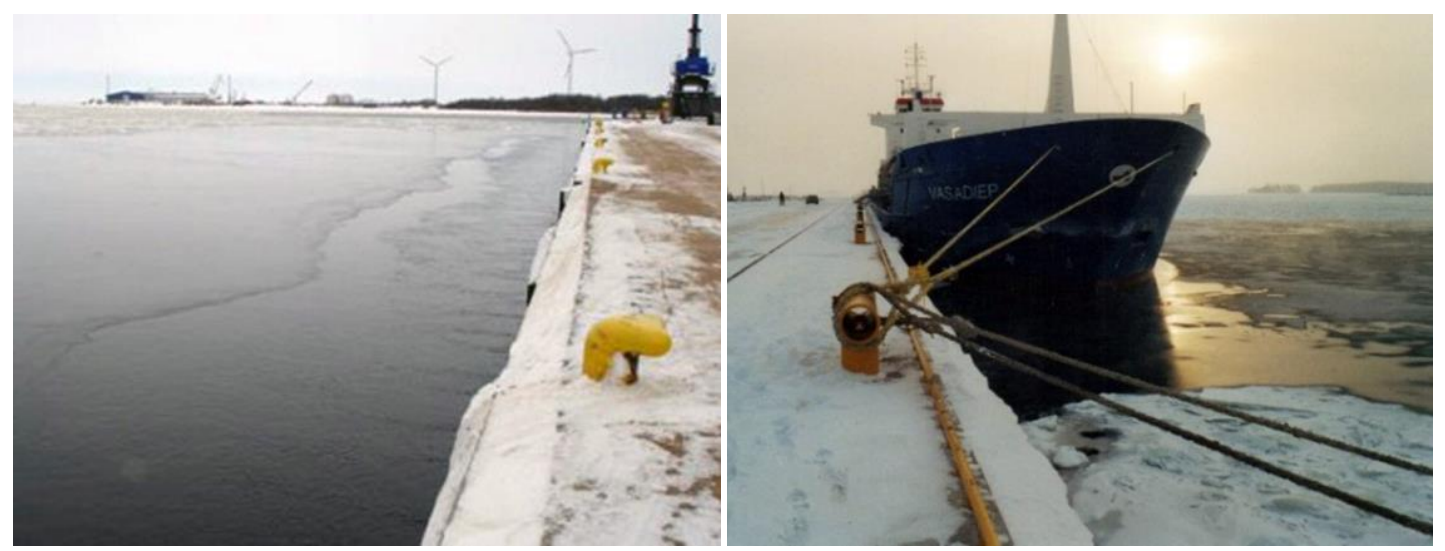

Figure 9. Left) Port of Oulu, Finland. Right) Use of propellers flow and manual mechanical removal in berthing place. (Courtesy of Eranti Engineering $O y$ ).

\section{Ice management fleet}

An ice management fleet is used to ease the ice conditions in navigation channels and the harbor basin, during escorting and berthing operations. The fleet consist of icebreaking tugs for close support as flushing in harbor areas (Figure 10), and icebreakers for escorting the vessels into the port (Figure 11 Left) and perform ice management in port (Figure 11 Right).

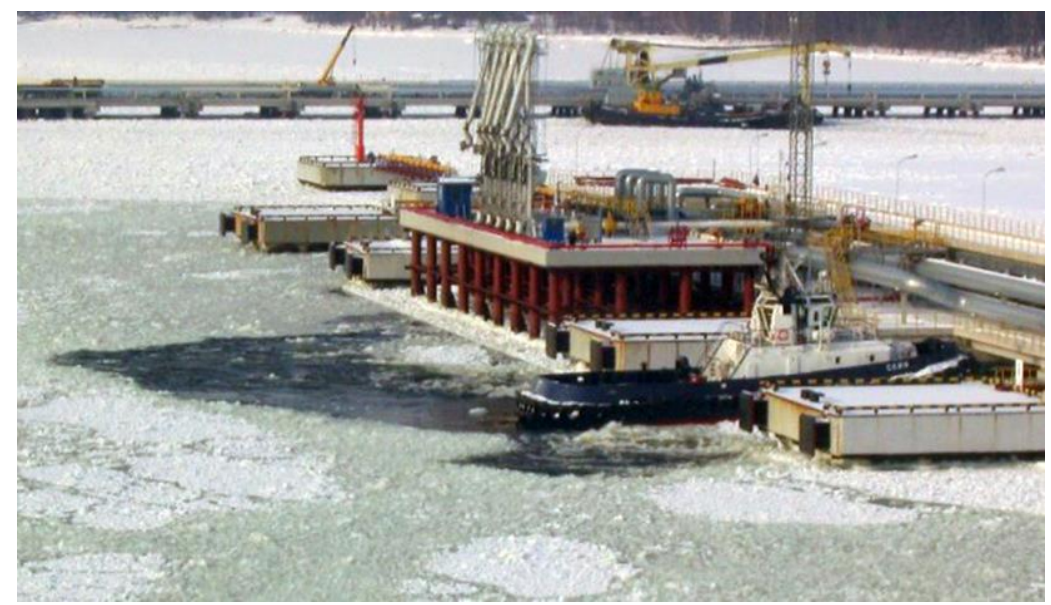

Figure 10. Tug flushing Primorsk Oil Terminal (Gulf of Finland) before vessel arrival.
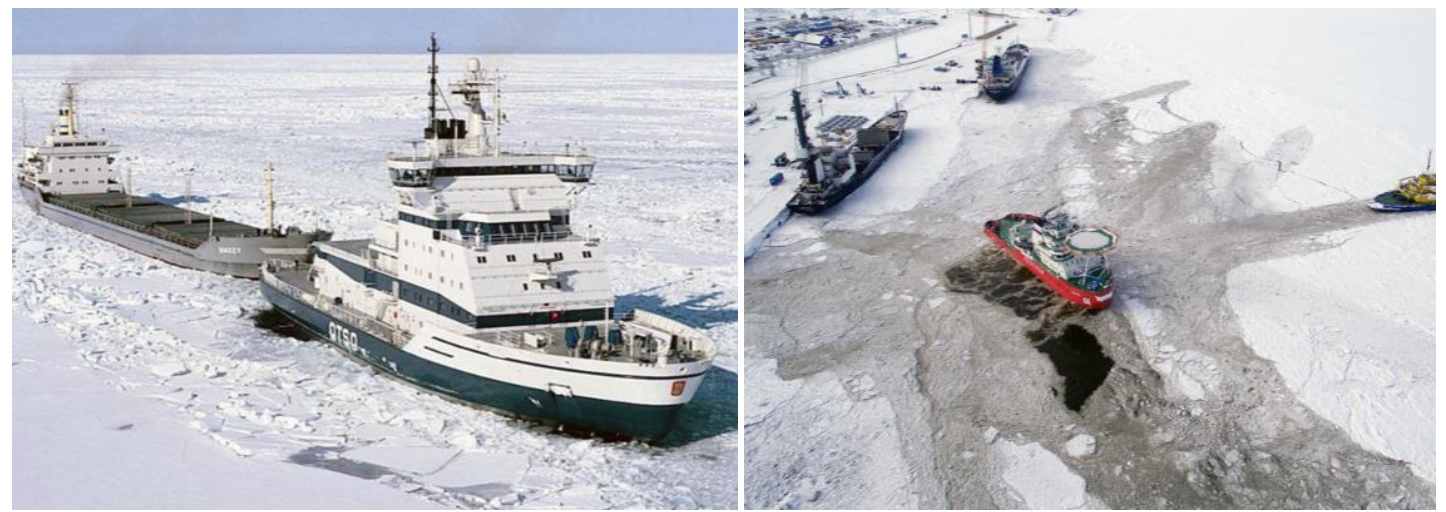

Figure 11. Left) Icebreaker Otso assisting in navigation. Right) Oblique icebreaker Baltika easing brash ice conditions in Sabetta port during ice trial in April 2015 (Ob Bay, Russia). 
One of the most significant Aker Arctic's references is the multipurpose icebreaker Baltika (Aker ARC 100), which can operate in oblique mode opening a wider navigation channel than conventional icebreakers would do (Figure 12). It was delivered in 2014, with icebreaking capability of 3 knots in 1 $\mathrm{m}$ level ice and ice class Icebreaker6. It is an emergency and rescue vessels, with oil spill combat capability.

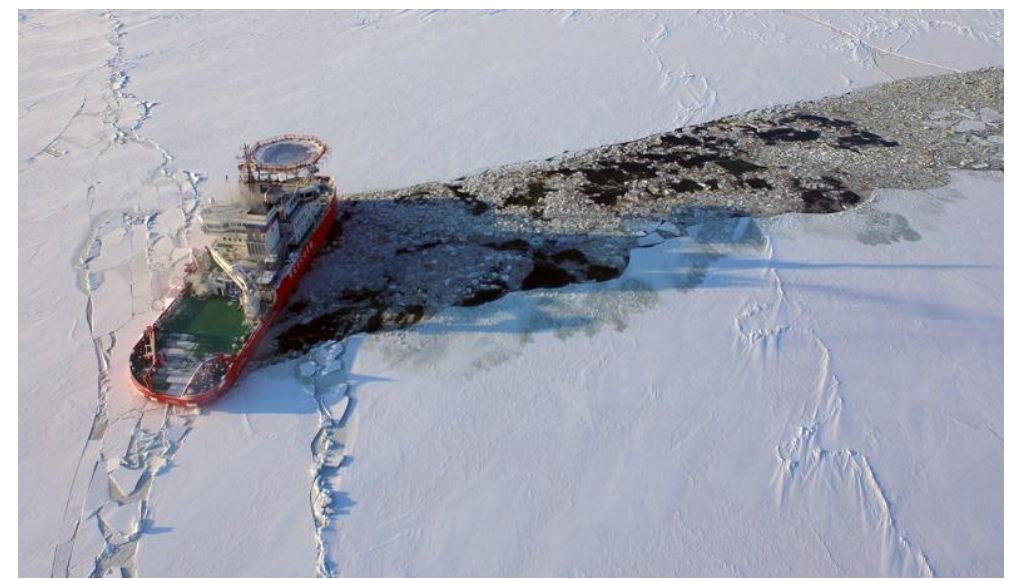

Figure 12. Oblique icebreaker Baltika performing in oblique mode during ice trials, winter 2015.

Other of the latest Aker Arctic's references is icebreaker Polaris (Aker ARC 130). It was delivered in 2016 and it is specially designed to operate in Baltic Sea, with icebreaking capability of 3.5 knots in $1.8 \mathrm{~m}$ level ice and ice class Polar Class 4 Icebreaker (+). Polaris is the world's first LNG fueled icebreaker (Figure 13).

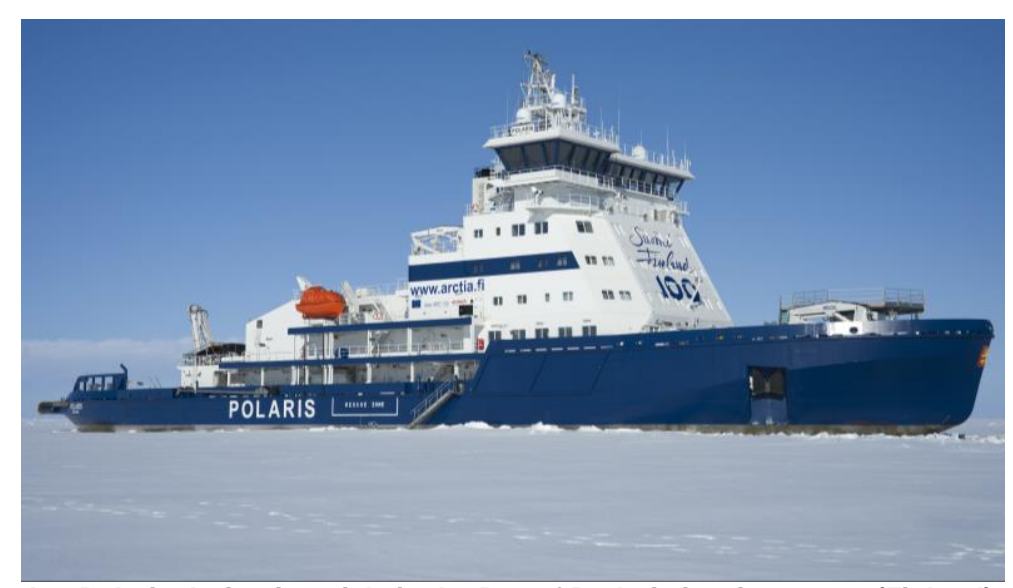

Figure 13. Icebreaker Polaris during ice trials in the Bay of Bothnia in winter 2017 (Finland).

\section{CONCLUSIONS}

There are no standard solutions for ice management in harbor areas. To complete a successful project with good functionality and operability under artic conditions, each location must be locally evaluated and carefully selected. Moreover, associated ice challenges are to be identified at an early stage of the project development. In addition, all marine structures, onshore equipment and systems must be specifically designed for cold areas. Finally, interaction between port and different vessels needs to be defined according to the related ice challenges and operational requirements to select the best ice management strategy and methods. 


\section{REFERENCES}

Eranti (1986): Cold region structural engineering, McGraw Hill Higher Education (1986). 529pp. ISBN 10: 0-07-037034-6.

Mironov, et al. (2012). Ice phenomena threatening arctic Shipping. Backbone publishing company. ISBN 978-0-9847864-2-8.

Pan, Eranti (2009): Flow and heat transfer simulations for the design of the Helsinki Vuosaari harbour ice control system, Cold Regions Science and Technology, ELSEVIER, vol. 55, issue 3, pp. 304310 .

Sandkvist (1981): Conditions in brash ice covered channels with repeated passages, POAC 81: the sixth international conference on port and ocean engineering under arctic conditions, Québec, Canada July 27-31, 1981, Proceedings, Universite Laval, 1981, 244-252 p.

Weeks (2010): On sea ice. University of Alaska Press (2010). Fairbanks, AK. 664pp. ISBN-13: 978-1602-23079-8. 